\title{
Lung injury and inflammation response by chronic intermittent hypoxia in rats
}

\author{
Huan $\mathrm{Lu}^{\dagger}$, Xiaodan $\mathrm{Wu}^{\dagger}$, Cuiping Fu, Jing Zhou and Shanqun $\mathrm{Li}^{*}$
}

\begin{abstract}
Background: Chronic intermittent hypoxia is the primary pathophsiological feature of obstructive sleep apnea/ hypopnea syndrome. The characteristics of $\mathrm{ClH}$ can be imitated by animal experiment models thus to study $\mathrm{ClH}$ related systemic organ injuries, including respiratory systems.

Methods: Sixteen male SD rats were randomly divided into two groups: $\mathrm{CIH}$ group $(n=8)$ and control group $(n=8)$. The $\mathrm{ClH}$ group was exposed to intermittent hypoxia circumstance for 5 weeks $(8 \mathrm{~h} /$ day) and control group was placed in the same animal chamber exposed to normal air circumstance. Between the two groups, the inflammatory factors of IL-6 and TNF- $a$ within serum and BALF were measured by ELISA; the structure and ultrastructure of lungs were evaluated by HE staining and electronmicroscopy. The nuclear factor-kB (NF-kB) in lung tissue was detected by Western blot.
\end{abstract}

Results: The concentration of IL- 6 and TNF-a in serum in CIH group increased significantly (138.63 \pm 43.82 vs. 41.82 $\pm 5.24 \mathrm{pg} / \mathrm{ml}$ and $126.62 \pm 34.81$ vs. $73.43 \pm 5.72 \mathrm{pg} / \mathrm{ml}$, both $P<0.05)$. The concentration of IL-6 and TNF- $a$ in BALF in $\mathrm{ClH}$ group was higher than that in control group $(67.1 \pm 24.2 \mathrm{pg} / \mathrm{ml}$ vs $39.8 \pm 21.5 \mathrm{pg} / \mathrm{ml}$ and $36.61 \pm 19.17 \mathrm{pg} / \mathrm{ml}$ vs $20.31 \pm 8.44 \mathrm{pg} / \mathrm{ml}$, respectively, $P<0.05)$. In the HE staining of lung tissue, results showed that severe inflammatory cell infiltration in alveolar walls and alveolar spaces was found in $\mathrm{CIH}$ group and the histological score of $\mathrm{ClH}$ group is higher significantly $(6.857 \pm 0.553$ vs. $2.286 \pm 0.286 \mathrm{~g}, P<0.05)$; In the electronmicroscopy of Typellalveolar cells, results showed that karyotheca and endoplasmic reticulum were damaged obviously in Type II alveolar cells. The NF-kB increased significantly in the $\mathrm{ClH}$ group compared with control group $(0.43 \pm 0.1$ vs $0.22 \pm$ $0.05, P<0.05)$.

Conclusions: Animal experiment model can be used to imitate the pathophysiologic changes of $\mathrm{ClH}$. There are systematic and local airway inflammation coexisting in $\mathrm{ClH}$ rats. $\mathrm{ClH}$ leads to inflammatory cell infiltration and organelle damages within lung tissues. We speculated that there was some correlation between inflammation and lung damages in $\mathrm{ClH}$ rats.

Keywords: Obstructive sleep apnea, Chronic intermittent hypoxia, Inflammation, NF-kB, Interleukin-6, Tumor necrosis factor-alpha, Rats

\section{Background}

Obstructive sleep apnea/hypopnea syndrome (OSAHS) is a common respiratory condition affecting approximately $3-7 \%$ of the middle-aged population (Lee et al. 2008; Tishler et al. 2003), characterized by apnea and hypopnea during sleep. Recurrent apnea and hyponea during sleep usually result in hypoxia/reoxygenation and

\footnotetext{
* Correspondence: li.shanqun@zs-hospital.sh.cn

${ }^{\dagger}$ Equal contributors

Department of Pulmonary Medicine, Clinical Center for Sleep Breathing Disorder and Snoring, Zhongshan Hospital, Fudan University, 180 Fenlin Road, Shanghai 200032, China
}

oxidative stress reaction, which can cause cell injury, inflammation and organ dysfunction (Spector 2000). Chronic intermittent hypoxia $(\mathrm{CIH})$ is the primary feature of OSAHS. CIH represents a specific form of hypoxia, which differs from sustained hypoxia and resembles reperfusion injury. Oxidative stress and inflammation promoted by repeated cycles of hypoxia/ reoxygenation have been proposed as possible underlying mechanisms, among others, predisposing to such as cardiovascular diseases, cerebrovascular diseases, metabolic diseases morbidity in OSAHS (Lavie 2003). 
Hypobaric hypoxia is a common animal model for hypoxic pulmonary hypertension. Pulmonary vasoconstriction and vascular remodeling mediated by hypoxia is the major pathophysiological characteristic of hypoxic pulmonary hypertension. Recent researches have found that chronic and intermittent hypoxia can both result in pulmonary hypertension through inducing pulmonary artery reconstruction (Fagan 2001). And clinical data also support the close connection between OSA and pulmonary hypertension (Ismail et al. 2015).

Moreover, systemic and local airway inflammation mediated by $\mathrm{CIH} / \mathrm{OSAHS}$ could induce lung injury to some degrees which might aggravate existing respiratory diseases, such as asthma and COPD (Ioachimescu and Teodorescu 2013). However, elucidation of the basic mechanisms of inflammation damage is limited by the genetic heterogeneity of OSAHS patients and the presence of multiple confounding and comorbid conditions, including obesity. Animal models make it possible to study the causative mechanisms and the consequences of nocturnal respiratory events avoiding the confounding factors that occur in humans.

In this study, we used our patent rat $\mathrm{CIH}$ model (Patent number: ZL 20092 0067224.9) to study lung injury during exposure to $\mathrm{CIH}$ and its potential association with inflammation. We do these initial work to understand comprehensively and deeply the mechanism of OSAHS related lung injury.

\section{Methods}

\section{Animals}

Male Sprague-Dawley (SD) rats (130-150 g) were supplied by experimental animal centre of Zhongshan Hospital affiliated to Fudan University (Shanghai, China). The animals were housed individually at a constant temperature $\left(23 \pm 2{ }^{\circ} \mathrm{C}\right)$ at a relative humidity of $60 \% \pm$ $2 \%$ on an automatically controlled $12 \mathrm{~h}$ light/dark cycle (lights on at 07:00 AM). They had free access to food and water except during experiments that required otherwise. At the end of experiment, rats were anesthetized with pentobarbital sodium $(40 \mathrm{mg} / \mathrm{kg})$ intraperitoneally. All experiments were carried out in accordance with the National Institutes of Health Guide for the Care and Use of Laboratory Animals of China. Every effort was made to minimize the number of animals used and any pain and discomfort that they might experience.

\section{Chronic intermittent hypoxia model}

$\mathrm{CIH}$ model used in the present study were similar to our described previously (Fu et al. 2015; Liu et al. 2014). 16 rats were randomly divided into two groups, eight in each group. One group was exposed to intermittent air (IA) and the other served as control. $\mathrm{CIH}$ group was exposed to intermittent hypoxia (IH). Both groups underwent treatment from 09:00 to 17:00 daily for 5 weeks. IA and $\mathrm{IH}$ animals were placed in identical intermittent hypoxia chamber of our own design filled with nitrogen and oxygen or with air, using a gas delivery system which we described in detail previously. Briefly, the fracion of inspiration $\mathrm{O}_{2}\left(\mathrm{FiO}_{2}\right)$ in the $\mathrm{IH}$ chamber fluctuated between 6 and $21 \%$, regulated by a gas control equipment through insufflation time and flow setting of nitrogen and oxygen. The oxygen concentration was measured automatically using an oxygen analyzer (Shanghai Medical Equipment, Shanghai, China). Every hypoxia/reoxygenation cycle took $1 \mathrm{~min}$, the sequence is as follows: pure nitrogen for $30 \mathrm{~s}$ $\left(\mathrm{FiO}_{2}\right.$ decreased to about 6-7\%)-rest for $10 \mathrm{~s}$-pure oxygen for $20 \mathrm{~s}\left(\mathrm{FiO}_{2}\right.$ increased to about 20-21\%). For the control group, the chamber was filled with air and $\mathrm{FiO}_{2}$ levels were kept stable at 20-21\%. We took 10 points of two planes in the chamber: plane 1 : point $A_{1}, B_{1}, C_{1}, D_{1}$, $E_{1}$, plane 2: point $A_{2}, B_{2}, C_{2}, D_{2}, E_{2}$ (Fig. 1a), the oxygen concentration changes of the 10 points were measured by the tester. After 10 cycles, we measured the oxygen
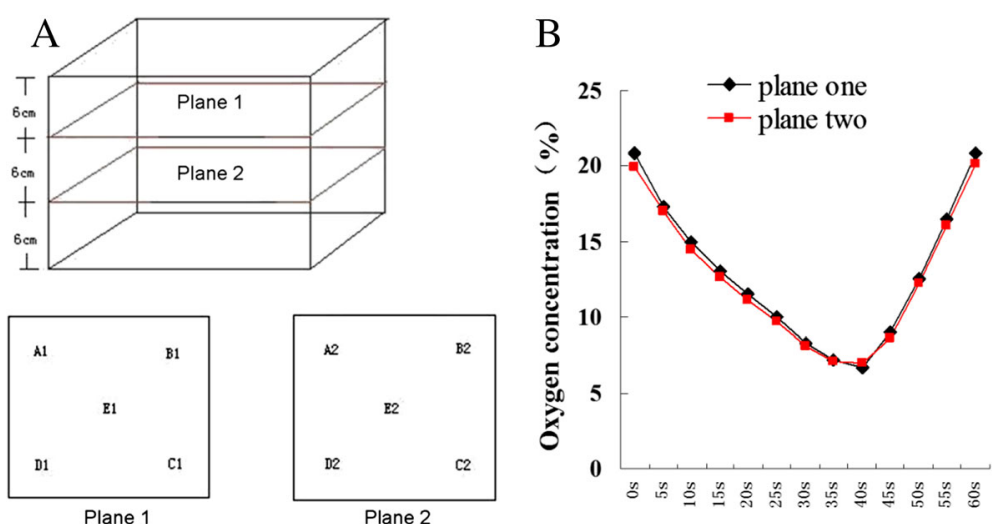

Fig. 1 Two planes and oxygen concentration change in the chamber. a Animal chamber is showed above. There are two planes and distribution of 10 points: the animals are placed in the plane 2; (b) The black curve represents plane one and the red curve represents plane two. Oxygen concentration in the chamber fluctuated between 6 and $7 \%$ to 20 and $21 \%$ 
concentration of one point every $5 \mathrm{~s}$ for 5 cycles, then next point for 5 cycles. The average concentration of five points in each plane was taken for Y-axis, and the different time points of a cycle were taken for X-axis. The curve showed that oxygen concentration in the chamber first decreased and then increased to normal, it fluctuated between 6 and $7 \%$ to 20 and $21 \%$ (Fig. 1b). Intermittent hypoxia triggers a bewildering array of both detrimental and beneficial effects in multiple physiological systems. Our $\mathrm{CIH}$ protocol consists of severe hypoxia (2-8\% inspired O2) and between 48 and 2,400 cycles/day (60 times/h* $8 \mathrm{~h}=480 \mathrm{cy}-$ cles/day) which are prone to pathology (Navarrete-Opazo and Mitchell 2014).

\section{Measurements}

\section{Wet/dry ratio measurement}

Lung tissues were removed from rats after anesthesia. Right middle lobe was weighed and placed in a $60{ }^{\circ} \mathrm{C}$ drying oven. After drying for $72 \mathrm{~h}$, it was weighed again, and then the wet/dry ratio was calculated.

\section{Histology and electronmicroscopy}

Right upper lobe was fixed in neutral formalin, embedded in paraffin wax, sliced and stained with hemagglutinin-esterase, then was observed in light microscope. The degree of lung injury was quantified based on the following ( $\mathrm{Su}$ et al. 2003)@@: alveolar and interstitial edema, inflammatory infiltration, and hemorrhage. The severity of injury was graded for three variables: no injury $=0$; injury to $25 \%$ of the field $=1$; injury to $50 \%$ of the field $=2$; injury to $75 \%$ of the field $=3$; and diffuse injury $=4$.

Right lower lobe was fixed in $4 \%$ glutaraldehyde and then $1 \%$ osmic anhydride, dehydrated by ethanol and acetone, embedded by 618 epoxy resin, sliced with thickness of $50 \mathrm{~nm}$ and dyed by uranyl acetate and lead citrate, then was observed in electronmicroscopy.

\section{Western blot analysis}

Lung tissues were lysed in a protein extraction buffer. The protease inhibitor of phenylmethylsulfonyl fluoride (PMSF) was added to the buffer with tissues. The samples were separated on 10\% SDS-polyacrylamide gels, and then transferred to a nitrocellulose membrane. The primary antibodies were NF- $\mathrm{KB}$ (65KD) and $\beta$-actin (42KD) antibody (Abcam, USA). The stripe signals were detected by ECL kit (Beyotime, China).

\section{Measurement of interleukin-6 (IL-6) and tumor necrosis factor-alpha (TNF- $a$ ) concentration in serum and bronchoal- veolar lavage fluid (BALF)}

After the experiment (the $36^{\text {th }}$ day), 4-5 ml blood was collected from abdominal aorta of each rat in two groups, and then centrifuged at a rate of $3000 \mathrm{rpm}$ for
$15 \mathrm{~min}$. The supernatant fluid was conserved in $-70{ }^{\circ} \mathrm{C}$ refrigerator. Rats were exanguinated from abdominal arota, then a cannula was intubated into the left bronchus. The left lung of each rat was lavaged with a total of $9 \mathrm{ml}$ neutral saline for three times with $3 \mathrm{ml}$ each time. The lavaged fluid was collected and centrifuged (3000 r/min) for $15 \mathrm{~min}$. The supernatant fluid was conserved in $-70{ }^{\circ} \mathrm{C}$ refrigerator. The concentration of IL-6 and TNF- $\alpha$ in serum and BALF were measured by ELISA kit (DAKEWE, China).

\section{Statistics}

Measurement data are shown as $\bar{x} \pm \mathrm{S}$. The comparisons of data among two groups were performed using independent sampler $t$-test. SPSS for windows Version 11.5 was used to do data processing. Significance was accepted when $P$ values $<0.05$.

\section{Results}

HE staining and electronmicroscopy of lung tissues

(Fig. 2)

In the HE staining of lung tissue, lung tissue structure is normal in the control group rats (Fig. 2d, f); Results showed that there were significant lung tissue inflammatory injuries in the $\mathrm{CIH}$ group rats (Fig. 2e, g): alveolar septum widen, alveolar wall thicken, lymphocytes and mononuclear cells infiltrate, alveolar space lessen; little exudation within alveolar space, septal capillary open and congest mildly, focal nodular pneumonia lesions were found partly. The histological score of $\mathrm{CIH}$ group is much higher than that in the control group $(6.857 \pm$ 0.553 vs. $2.286 \pm 0.286 \mathrm{~g}, P<0.05)$.

In the electronmicroscopy of TypeIIalveolar cells, no abnormality was found in karyotheca and endoplasmic reticulum in the control group (Fig. 2a); Swelled nuclear membrane, outstretched endoplasmic reticulum, increased lamellar body and vacuolar degeneration were found in the CIH group (Fig. 2b and c).

\section{Inflammation response of $\mathrm{ClH}$ rats (Fig. 3)}

\section{Weight changes (Fig. 3d)}

There was no statistical difference of rats weight between two groups before the experiment. After the experiment (the $36^{t} \mathrm{~h}$ day), body weight of rats in $\mathrm{CIH}$ group was lower than that in control group (359.11 \pm 12.86 vs $469.61 \pm 16.87 \mathrm{~g}, P<0.05)$.

\section{Wet/Dry ratio (Fig. 3c)}

The wet/dry ratio of lung tissue in the CIH group is higher than that of in the control group (5.390 \pm 0.460 vs $4.105 \pm 0.481, P<0.05)$. The lung wet-to-dry weight ratio reflects lung edema. Lung edema was found in the $\mathrm{CIH}$ group. 


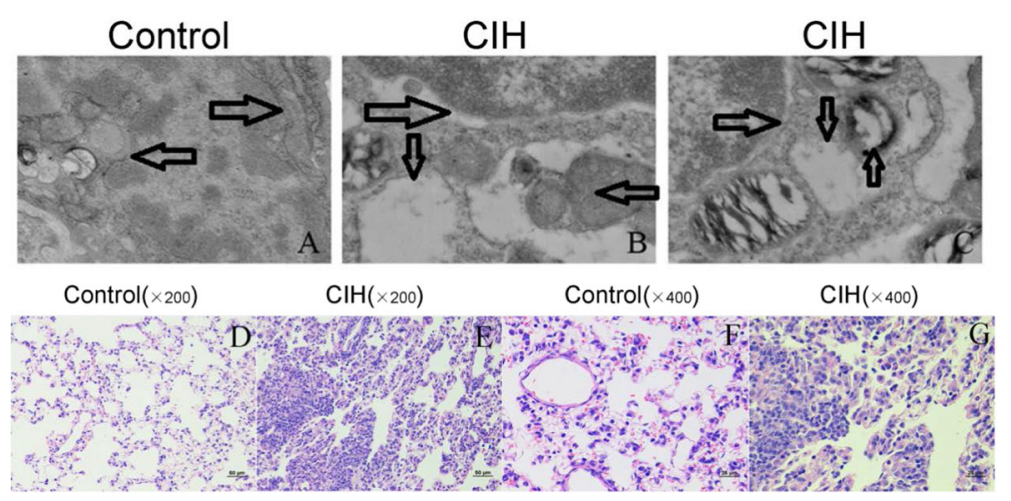

Fig. 2 Electronmicroscopy and Histopathology of lung tissue. a-c Ultrastructure of Type II alveolar cells under scanning electronmicroscope. a No change happened in karyotheca and endoplasmic reticulum in the control group; b Swelled nuclear membrane, outstretched endoplasmic reticulum and vacuolar degeneration appeared in the $\mathrm{ClH}$ group rats; c Swelled nuclear membrane, increased Lamellar body and vacuolar degeneration in the $\mathrm{ClH}$ group). $\rightarrow$ pointed to the karyotheca; $\leftarrow$ pointed to endoplasmic reticulum; $\downarrow$ pointed to vacuolar degeneration; $\uparrow$ pointed to Lamellar body. $\mathbf{d}-\mathbf{g}$ H\&E staining of lung tissue (200x and 400x). d, $\mathbf{f}$ The structure of lung tissue is normal in the control group rats; $(\mathbf{e}, \mathbf{g}) \mathrm{HE}$ staining results showed that there were significant lung tissue inflammatory injuries in the CIH group rats: alveolar septum widen, alveolar wall thicken, lymphocytes and mononuclear cells infiltrate, alveolar space lessen; little exudation within alveolar space, septal capillary open and congest mildly, focal nodular pneumonia lesions were found partly

\section{NF-KB (Fig. 3a, b)}

$\mathrm{NF}-\mathrm{KB}$ is a protein transcription factor that is required for maximal transcription of many proinflammatory molecules which are important in the generation of inflammation. In western blot analysis lung tissue, the NF$\kappa B$ increased significantly in the $\mathrm{CIH}$ group compared with control group $(0.43 \pm 0.1$ vs $0.22 \pm 0.05, P<0.05)$.

\section{IL- 6 and TNF- $\alpha$ (Fig. 3e)}

IL- 6 and TNF- $\alpha$ are pro-inflammatory factors secreted by mononuclear macrophage, vascular endothelial cell and T lymphocyte. The concentration of IL- 6 and TNF$\alpha$ in serum indicating systemic inflammation in $\mathrm{CIH}$ group were higher than that in control group $(138.63 \pm$ 43.82 vs $41.82 \pm 5.24 \mathrm{pg} / \mathrm{ml}$ and $126.62 \pm 34.81$ vs 73.43
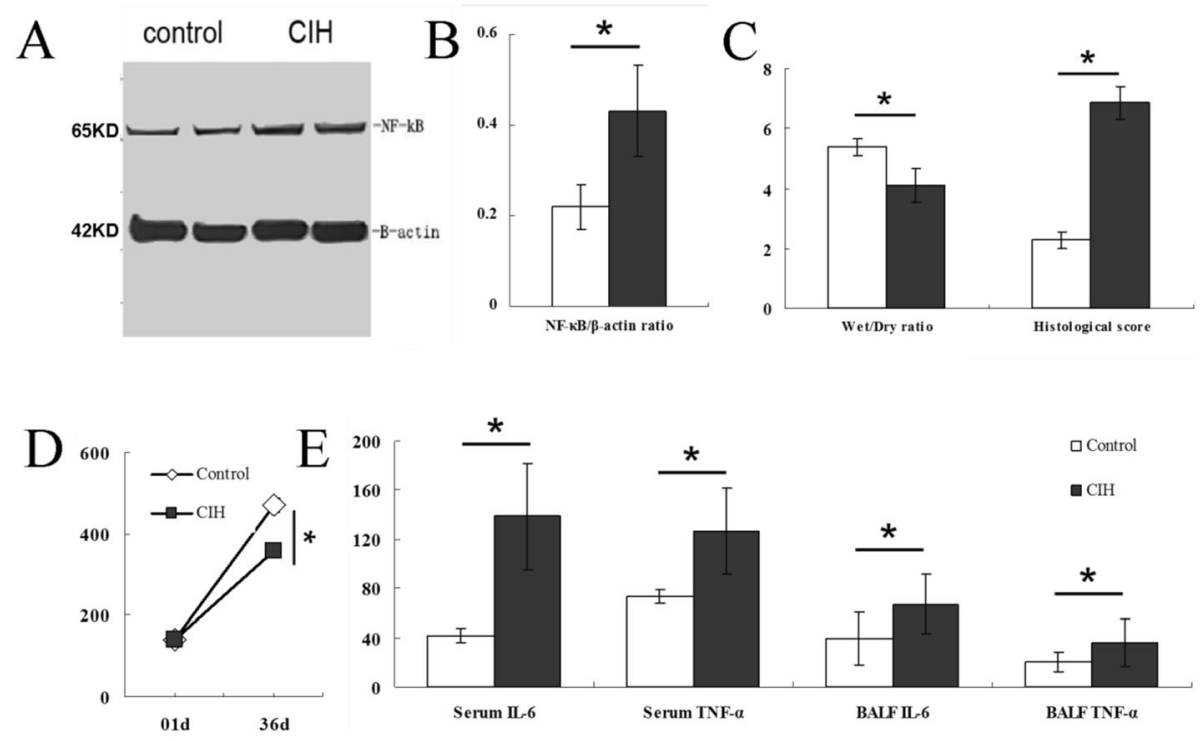

Fig. 3 Systematic and lung tissue local inflammation changes within $\mathrm{CIH}$ rats. a Western blotting results of NF-KB protein levels in the lung tissue; (b) Bar graph shows the statistic results of NF-KB protein levels; (c) Lung wet-to-dry ratio $(n=8)$ and histological scores $(n=8)$; (d) Body weight change of rats: $01 \mathrm{~d}$, the first day of experiment and 36d, the end of the experiment; (e) Concentration of IL- 6 and TNF-a in serum and BALF. *, $P<0.05$ compared with control group $(n=8)$. All results are means \pm SEM 
$\pm 5.72 \mathrm{pg} / \mathrm{ml}$, respectively, $P<0.05)$. The concentration of IL- 6 and TNF- $\alpha$ in BALF indicating local airway inflammation in $\mathrm{CIH}$ group was higher than that in control group $(67.1 \pm 24.2 \mathrm{pg} / \mathrm{ml}$ vs $39.8 \pm 21.5 \mathrm{pg} / \mathrm{ml}$ and $36.61 \pm 19.17 \mathrm{pg} / \mathrm{ml}$ vs $20.31 \pm 8.44 \mathrm{pg} / \mathrm{ml}$, respectively, $P<0.05)$.

\section{Discussion}

Obstructive sleep apnea (OSA) is associated with repetitive nocturnal arterial oxygen desaturation and hypercapnia, large intrathoracic negative pressure swings, and acute increases in pulmonary artery pressure. $\mathrm{CIH}$ is the typical and primary pathophsiological feature of OSA. According to the hypoxia patterns, hypoxia model can be divided into hypobaric hypoxia, sustained hypoxia, intermittent continuous hypoxia and chronic intermittent hypoxia, among which $\mathrm{CIH}$ is the optimal model imitating the pathophsiological feature of OSA.

The core of pathophysiologic changes of CIH/OSA related multiple organs injury is inflammation response, including lung. Initial clinical study showed that OSAHS patients usually develop both systematic and local inflammation, and the former is characterized by elevation of inflammatory factors in plasma. Serum levels of different inflammatory markers were significantly increased in patients with the combination of sleep apnea, including hs-CRP, IL1-Ra, IL-8, IL-6, TNF- $\alpha$, Rantes and sICAM. A meta-analysis addressed the profile of the inflammatory markers in OSAHS of multiple small size studies (Nadeem et al. 2013): Standardized pooled Mean differences were calculated to be 1.77 for CRP, 2.16 for IL-6, 1.03 for TNF- $\alpha, 4.22$ for IL-8, 2.93 for ICAM, 1.45 for Selectins and 2.08 for VCAM. Continuous positive airway pressure (CPAP) is the primary treatment for OSAHS. Evidence shows that CPAP therapy reduces inflammation Severity. Another meta-analysis to study the effects of CPAP usage for patients with OSA significantly decreases serum inflammatory markers CRP, IL-6 and TNF- $\alpha$ (Baessler et al. 2013). IL-6 and TNF- $\alpha$ are proinflammatory factors secreted by mononuclear macrophage, vascular endothelial cell and $\mathrm{T}$ lymphocyte. In our study, systemic inflammation changes induced by $\mathrm{CIH}$ are apparent: IL-6 and TNF- $\alpha$ were significantly higher in $\mathrm{CIH}$ rats, which is an indirect index for successful $\mathrm{CIH}$ model. Animal models make it possible to study the causative mechanisms and the consequences of nocturnal respiratory events avoiding the confounding factors that occur in humans (such as obesity).

In addition to systemic inflammation, OSAHS patients also develop inflammation in local airway. Local inflammation is due to a structural and functional change of local airway, and congestion and edema of lung tissue resulted from recurrent obstruction and opening during sleep. Recurrent hypoxia/reoxygenation produces excessive oxygen free radicals, which injures local tissue and results in a high inflammatory factor status. Carpagnano et al. (Carpagnano et al. 2002) measured IL-6 in EBC of OSAHS patients and found a local inflammation in lower respiratory tract. Kensaku Aihara et al. found in OSAHS patients sputum IL-6, IL-8, TNF- $\alpha$, and VEGF were significantly related to sputum neutrophil number, and sputum IL-8 and TNF- $\alpha$ were related to proximal airway resistance independently of BMI (Aihara et al. 2013). However, such study was mainly limited in clinical investigation. In our study, IL- 6 and TNF- $\alpha$ in serum and BALF in CIH group was significantly higher than that in control group. Our results demonstrated both local inflammation and systemic inflammation were consistent with most of clinical study.

Transcription factor nuclear factor $k B(N F-k B)$ is a master regulator of inflammatory gene expression and regulates cytokines such as TNF-a and IL-8 that contribute to atherosclerosis by inducing adhesion molecule expression (Hansson, 2005). Results on experiments animals and cell cultures have shown that $\mathrm{IH}$ activates a variety of transcription factors including the hypoxiainducible factor-1 (HIF-1), NF-kB, c-fos (immediate early gene) and nuclear factor of activated T-cells (NFAT) (Nanduri et al. 2008), which regulate many genes that promote tissue perfusion and oxygenation (Garvey et al. 2009). In the lung tissue western blot results, the concentration of NF-kB in the $\mathrm{CIH}$ group increased significantly. The results suggested that chronic intermittent hypoxia activate inflammatory pathways in the lung tissue.

Inflammation in OSAHS can cause pathophysiologic change of several organs, and finally, the structure and function of organs are injured. The result showed the wet/dry ratio of CIH group was higher than that of control group, which hinted that $\mathrm{CIH}$ rats develop obvious edema of lung tissue. And pathological examination showed lung $\mathrm{HE}$ staining of $\mathrm{CIH}$ rats had all developed severe alveolar inflammation and some of them had developed diffuse lobular pneumonia. Our electronmicroscopy results showed that karyotheca and endoplasmic reticulum injuries of Type II alveolar cells were serious in the $\mathrm{CIH}$ group. Pulmonary edema as a resenting feature of sleep apnea syndrome has also been found in our animal model. Makarenko et al found that IH decreased transendothelial electrical resistance (TEER) suggesting attenuated endothelial barrier function which were induced by oxidative stress (Makarenko et al. 2014). Disruption of barrier function not only affects pulmonary gas exchange but also leads to pulmonary edema. Mild pulmonary edema, alteration of alveolarization process, and impairment of alveolar wall have been observed in the lung of subjects with OSA. CIH could produce a severe impact on pulmonary surfactant performance and may lead to collapse of the alveoli. Liang 
Shao et al found that serum surfactant protein B (one of pulmonary surfactants) might be a potential biomarker to diagnose OSA (Shao et al. 2016).

Recent researches have found that chronic and intermittent hypoxia both can result in pulmonary hypertension through inducing pulmonary artery reconstruction. In our previous $\mathrm{CIH}$ rat experiments (Wu et al. 2011), echocardiogram results showed that compared to control group, the value of pulmonary arterial flow in $\mathrm{CIH}$ group increased significantly which could be due to vasoconstriction induced by repeated cycles of hypoxia/ reoxygenation. Intermittent chronic hypoxia was used to mimic a severe hypoxic pulmonary hypertension $(\mathrm{HPH})$ condition. Haifeng Jin et al found that chronic intermittent hypoxia-induced inflammation and excessive proliferation of pulmonary artery smooth muscle cells play important roles in the pathological process of hypoxic pulmonary hypertension (Jin et al. 2014). Chronic intermittent hypoxia elicits milder effects on pulmonary artery medial layer muscularization and subsequent right ventricular hypertrophy than chronic hypoxia (Ramirez et al. 2012). Clinical studies show that pulmonary hypertension associated with OSA appears to be mild and may be due to a combination of precapillary and postcapillary factors including pulmonary arteriolar remodeling and hyperreactivity to hypoxia and left ventricular diastolic dysfunction and left atrial enlargement (Sajkov and Mcevoy 2009). Inflammation participates in the initiation and progression of HPH by actively contributing to chronic vasoconstriction and remodeling of the pulmonary vessel wall. Hisashi Nagai et al (Nagai et al. 2015) demonstrated that pro-inflammatory pulmonary macrophages attenuate hypoxic pulmonary vasoconstriction via the activation of $\beta 3 \mathrm{AR} / \mathrm{iNOS}$ signaling in $\mathrm{IH}$ rats. It was a regret that we did not investigate the pressure change of pulmonary vessels.

In the clinical practice, OSA is more commonly seen in patients with obstructive lung diseases (OLD) such as asthma and COPD, perhaps as a result of shared risk factors and OSA is associated with worse clinical outcomes in patients with OLD, and continuous positive airway pressure therapy has potential beneficial effects on these vicious pathophysiological interaction. In OSA patients, local airway or systemic inflammatory state could exacerbate COPD or asthma which should be paid more attention by clinical physicians. Our animal results totally support the existing of systemic and local inflammation within lung of $\mathrm{CIH}$.

\section{Conclusions}

In our $\mathrm{CIH}$ rats model, histopathology and electronmicroscopy results of lung tissue confirmed the damage effects. The changes of transcription factor NF-kB and pro-inflammatory factors IL- 6 and TNF- $\alpha$ both indicated the existing systemic and local inflammation which may induce the lung injuries. Further explorations of $\mathrm{CIH}$ related inflammation damage occurrence mechanism are needed. Our rat $\mathrm{CIH}$ model can be effectively used to imitate the pathophysiologic changes of $\mathrm{CIH} / \mathrm{OSA}$.

\section{Acknowledgements \\ Thanks for ZiLong Liu PhD who provided professional and detailed writing services for this manuscript.}

\section{Funding}

This work is supported by a research grant from Shanghai Committee of Science and Technology (No. 13430720500), Shanghai Leading Academic Discipline Project (No. B115) and National Natural Science Foundation of China (No. 81570081), and Shanghai family planning and health committee (No. 2016HP020).

\section{Availability of data and materials}

All data generated or analysed during this study are included in this published article [and its supplementary information files].

Authors' contributions

SL and ZJ designed the study; HL, CF and WX all contributed to the completion of animal experiments; WX and ZJ assumed responsibility for the integrity of the data in the study; $\mathrm{HL}$ and $W X$ analysed the data and $\mathrm{HL}$ wrote the paper; SL contributed to critical review and final approval of the manuscript. All of the authors read and approved the final manuscript.

\section{Competing interests}

The authors declare that they have no competing interests.

\section{Consent for publication}

All authors gave their consents for the publication.

\section{Ethics approval and consent to participate}

The experimental protocol was approved by the local Animal Care and Use Committee of FudanUniversity and performed accordingly in agreement with the Helsinki Declaration of 1975, as revised in 1983.

Received: 1 August 2016 Accepted: 22 December 2016 Published online: 06 February 2017

\section{References}

Aihara K, Oga T, Chihara Y, Harada Y, Tanizawa K, Handa T, Hitomi T, Uno K, Mishima $M$, Chin K. Analysis of systemic and airway inflammation in obstructive sleep apnea[J]. Sleep and Breathing. 2013;17(2):597-604.

Baessler A, Nadeem R, Harvey M, Madbouly E, Younus A, Sajid H, Naseem J, Asif A, Bawaadam H. Treatment for sleep apnea by continuous positive airway pressure improves levels of inflammatory markers - a meta-analysis[J]. J Inflamm (Lond). 2013;10:13.

Carpagnano GE, Kharitonov SA, Resta O, Foschino-Barbaro MP, Gramiccioni E, Barnes PJ. Increased 8-isoprostane and interleukin-6 in breath condensate of obstructive sleep apnea patients[J]. Chest. 2002;122(4):1162-7.

Fagan KA. Selected contribution: pulmonary hypertension in mice following intermittent hypoxia[J]. J Appl Physiol (1985). 2001;90(6):2502-7.

Fu C, Jiang L, Zhu F, Liu Z, Li W, Jiang H, Ye H, Kushida CA, Li S. Chronic intermittent hypoxia leads to insulin resistance and impaired glucose tolerance through dysregulation of adipokines in non-obese rats[J]. Sleep and Breathing. 2015;19(4):1467-73.

Garvey JF, Taylor CT, Mcnicholas WT. Cardiovascular disease in obstructive sleep apnoea syndrome: the role of intermittent hypoxia and inflammation[J]. Eur Respir J. 2009;33(5):1195-205.

Hansson GK. Mechanisms of disease-Inflammation, atherosclerosis, and coronary artery disease[J]. N Engl J Med. 2005;352(16):1685-95.

loachimescu OC, Teodorescu M. Integrating the overlap of obstructive lung disease and obstructive sleep apnoea: OLDOSA syndrome[J]. Respirology. 2013;18(3):421-31.

Ismail K, Roberts K, Manning P, Manley C, Hill NS. OSA and pulmonary hypertension: time for a new look[J]. Chest. 2015;147(3):847-61. 
Jin H, Wang Y, Zhou L, Liu L, Zhang P, Deng W, Yuan Y. Melatonin attenuates hypoxic pulmonary hypertension by inhibiting the inflammation and the proliferation of pulmonary arterial smooth muscle cells[]]. J Pineal Res. 2014:57(4):442-50.

Lavie L. Obstructive sleep apnoea syndrome - an oxidative stress disorder[]]. Sleep Med Rev. 2003;7(1):35-51.

Lee W, Nagubadi S, Kryger MH, Mokhlesi B. Epidemiology of obstructive sleep apnea: a population-based perspective[]]. Expert Rev Respir Med. 2008;2(3):349-64

Liu Z, Jiang L, Zhu F, Fu C, Lu S, Zhou J, Wu X, Bai C, Li S. Chronic intermittent hypoxia and the expression of orexin and its receptors in the brains of rats[]]. Sleep Biol Rhythms. 2014;12(1):22-9.

Makarenko W, Usatyuk PV, Yuan G, Lee MM, Nanduri J, Natarajan V, Kumar GK, Prabhakar NR. Intermittent hypoxia-induced endothelial barrier dysfunction requires ROS-dependent MAP kinase activation[J]. AJP: Cell Physiology. 2014;306(8):C745-52.

Nadeem R, Molnar J, Madbouly EM, Nida M, Aggarwal S, Sajid H, Naseem J, Loomba R. Serum inflammatory markers in obstructive sleep apnea: a meta-analysis[]]. J Clin Sleep Med. 2013;9(10):1003-12.

Nagai H, Kuwahira I, Schwenke DO, Tsuchimochi H, Nara A, Ogura S, Sonobe T, Inagaki T, Fujii Y, Yamaguchi R, Wingenfeld L, Umetani K, Shimosawa T, Yoshida K, Uemura K, Pearson JT, Shirai M. Pulmonary macrophages attenuate hypoxic pulmonary vasoconstriction via $\beta 3$ AR/iNOS pathway in rats exposed to chronic intermittent hypoxia[]]. PLoS One. 2015;10(7): e131923.

Nanduri J, Yuan G, Kumar GK, Semenza GL, Prabhakar NR. Transcriptional responses to intermittent hypoxia[J]. Respir Physiol Neurobiol. 2008;164(1-2):277-81.

Navarrete-Opazo A, Mitchell GS. Therapeutic potential of intermittent hypoxia: a matter of dose[J]. Am J Physiol Regul Integr Comp Physiol. 2014;307(10):R1181-97.

Ramirez TA, Jourdan-Le SC, Joy A, Zhang J, Dai Q. Chronic and intermittent hypoxia differentially regulate left ventricular inflammatory and extracellular matrix responses.[J]. Hypertens Res. 2012;35(8):811-8.

Sajkov D, Mcevoy RD. Obstructive sleep apnea and pulmonary hypertension[J]. Prog Cardiovasc Dis. 2009;51(5):363-70.

Shao L, Li N, Yao X, Heizati M, Abdireim A, Wang Y, Abulikemu Z, Zhang D, Chang G, Zhou L, Hong J, Zhang Y, Kong J, Zhang X. Relationship between surfactant proteins $B$ and $C$ and obstructive sleep apnea: is serum SP-B concentration a potential biomarker of obstructive sleep apnea?[J]. Sleep and Breathing. 2016;20(1):25-31.

Spector A. Review: oxidative stress and disease[J]. J Ocul Pharmacol Ther. 2000;16(2):193-201.

Su X, Bai C, Hong Q, Zhu D, He L, Wu J, Ding F, Fang X, Matthay MA. Effect of continuous hemofiltration on hemodynamics, lung inflammation and pulmonary edema in a canine model of acute lung injury[]]. Intensive Care Med. 2003;29(11):2034-42.

Tishler PV, Larkin EK, Schluchter MD, Redline S. Incidence of sleep-disordered breathing in an urban adult population[J]. JAMA. 2003.

Wu X, Huang J, Kong D, Shao C, Zhou J, Lu S, Li S. Establishment of a rat chronic intermittent hypoxia model and evaluation by echocardiogram[J]. Fudan Univ J Med Sci. 2011;06:481-4.

\section{Submit your next manuscript to BioMed Central and we will help you at every step:}

- We accept pre-submission inquiries

- Our selector tool helps you to find the most relevant journal

- We provide round the clock customer support

- Convenient online submission

- Thorough peer review

- Inclusion in PubMed and all major indexing services

- Maximum visibility for your research

Submit your manuscript at www.biomedcentral.com/submit

) Biomed Central 